\title{
BMJ Open Perception of electronic cigarettes in the general population: does their usefulness outweigh their risks?
}

\author{
Jose M Martínez-Sánchez, ${ }^{1,2,3}$ Marcela Fu, ${ }^{1,2,4}$ Juan Carlos Martín-Sánchez, ${ }^{3}$ \\ Montse Ballbè, ${ }^{1,2,4,5}$ Esteve Saltó, ${ }^{6,7}$ Esteve Fernández ${ }^{1,2,4}$
}

To cite: Martínez-

Sánchez JM, Fu M, MartínSánchez JC, et al. Perception of electronic cigarettes in the general population: does their usefulness outweigh their risks?. BMJ Open 2015;5: e009218. doi:10.1136/ bmjopen-2015-009218

- Prepublication history for this paper is available online To view these files please visit the journal online (http://dx.doi.org/10.1136/ bmjopen-2015-009218).

Received 27 June 2015 Revised 1 September 2015 Accepted 10 September 2015

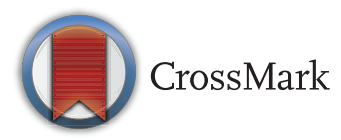

For numbered affiliations see end of article.

Correspondence to Dr Jose M Martínez-Sánchez; jmmartinez@iconcologia.net

\section{ABSTRACT}

Objective: To describe and compare the perceptions of the general population about the harmful effects of electronic cigarettes (e-cigarettes) on users and on those passively exposed to e-cigarettes and the perceptions about e-cigarette usefulness for reducing or eliminating tobacco smoking.

Design, setting, and participants: We analysed cross-sectional data from a longitudinal study of a representative sample of the general adult ( $\geq 16$ years) population of Barcelona, Spain (336 men and 400 women). The fieldwork was conducted between May 2013 and February 2014. We computed the percentages, adjusted OR and their corresponding 95\% $\mathrm{Cl}$ among participants with some awareness of e-cigarettes $(79.2 \%$ of the sample).

\section{Primary and secondary outcome measures:}

We assessed the perception about harmfulness for e-cigarette users and for passively exposed non-e-cigarette users, as well as the perception of usefulness for smokers of cigarette cessation and reduction.

Results: In this sample, $40.1 \%$ thought that e-cigarettes had a harmful effect on users, and $27.1 \%$ thought that e-cigarettes had a harmful effect on passively exposed bystanders $(p<0.001)$. Particularly, more never-smokers perceived that e-cigarettes had harmful effects on passively exposed bystanders than current smokers $(34.4 \%$ vs $20.6 \%$; OR $=1.93,95 \% \mathrm{Cl}$ 1.02 to 3.63). More people perceived e-cigarettes as being useful for reducing smoking than for quitting $(50.6 \%$ vs $29.9 \%, p<0.001)$, as well as for reducing smoking than as being harmful to users $(50.6 \%$ vs $40.1 \%, p=0.044$ ).

Discussion: The perception that e-cigarettes are useful for reducing tobacco consumption was more prevalent than the perception that e-cigarettes are harmful to users and to those passively exposed to e-cigarettes. Advertisements and messages about the use of e-cigarettes and their harmful effects should be regulated and based on scientific evidence to avoid creating erroneous ideas about their use.

\section{INTRODUCTION}

Interest in electronic cigarettes, also called 'e-cigarettes' or electronic nicotine delivery

\section{Strengths and limitations of this study}

- General population belief that e-cigarettes are more useful as tools for reducing tobacco consumption than as tools for quitting smoking entirely ( $50 \%$ vs $30 \%$ of the population).

- More people believe that e-cigarettes are useful, particularly for reducing tobacco consumption, than people who think that they have potentially harmful effects on users and on those passively exposed to e-cigarettes.

- The main limitation of our study is the attrition of the cohort in the follow-up. Also, this is a cross-sectional study and it is only possible to assess associations, but no causal relationships.

- We used a face-to-face questionnaire with trained interviewers, thus increasing the internal validity of our results.

systems, has increased rapidly around the world in recent years. Furthermore, awareness of e-cigarettes and the prevalence of users doubled in just a few years in the USA. $^{1-3}$ The prevalence of ever e-cigarette use among the general population is currently around 7\% both in Europe ${ }^{4}$ and in the USA. ${ }^{2}$ Since their commercialisation, e-cigarettes have polarised researchers and the general population in terms of their perceptions of their usefulness and potentially harmful effects. Some researchers and citizens, particularly smokers, e-cigarette users and stakeholders, advocate e-cigarettes as a useful tool for reducing or eliminating smoking; it has even been suggested that e-cigarettes represent a harm reduction strategy for smokers. ${ }^{5}$ On the other hand, most tobacco control researchers and tobacco control activists consider e-cigarettes a way to renormalise smoking in public and workplaces and to contribute to nicotine addiction among young people, including those who have never smoked. ${ }^{6}$ The WHO calls for regulation of e-cigarettes. 
There is growing scientific evidence related to public awareness and the prevalence of e-cigarette use. ${ }^{7} 8$ However, the risks and benefits of e-cigarette use, particularly at mid-term and long term, are still unknown, leading to increasing debate in scientific journals and in the media. In order to create rational and meaningful regulations in the future, it is especially important that we obtain information about the general population's perception of the harmful health effects of e-cigarettes and their usefulness for reducing or eliminating smoking. Currently, although there are some studies ${ }^{8-12}$ conducted in different populations about the perception of harmfulness and usefulness of e-cigarettes, the evidence is still scarce in Europe. Moreover, all these studies used the conventional cigarettes as a reference; however, none of these studies have compared the perceptions about the harmful effects of e-cigarettes with their usefulness. Currently, the harmful effects of tobacco consumption and passive exposure to tobacco smoke are well known. Thus, we hypothesise that any comparison with other products may lead to a perception of 'no risk' instead of 'less risk'. For this reason, the comparison of the harmful effects of e-cigarettes with the conventional tobacco could create a misclassification of the real perception of the population.

This study aimed to describe and compare the perceptions about the potential harmful effects of e-cigarettes and their usefulness for reducing or quitting tobacco smoking in the general population of Barcelona (Spain).

\section{METHODS}

We used the follow-up data from the Determinants of Cotinine phase 3 project (dCOT3, website: http:// bioinfo.iconcologia.net/es/content/estudio-dcot3). This project is a longitudinal study of a representative sample of the adult ( $\geq 16$ years) population of the city of Barcelona (Spain) ( $\mathrm{n}=1245 ; 694$ women and 551 men). The baseline survey was conducted between 2004 and 2005, and its detailed design is provided elsewhere. ${ }^{13} 14$ We followed up all the adult participants who responded to the face-to-face questionnaire in 2004-2005 and agreed to participate in future studies by providing a written and signed informed consent. We located 1010 of the 1245 participants $(81.1 \%)$ in the baseline study using the Insured Central Registry of Catalonia: $101 \mathrm{had}$ died, 49 moved out of the province of Barcelona, and 85 did not give consent to be followed or the informed consent was not requested because they were minors (<18 years in 2004-2005). In February 2013, we sent these 1010 people a letter reporting again the primary findings of the 2004-2005 study and informing them that an interviewer would go to their home to administer another face-to-face questionnaire. The follow-up survey was conducted between May 2013 and February 2014. Of those who were sent a letter, $72.9 \%$ agreed to participate and responded to the questionnaire, $18.5 \%$ refused to participate in the follow-up, $7.2 \%$ moved elsewhere and $1.3 \%$ died. From 736 individuals followed up (336 men and 400 women), 583 (79.2\%) answered 'yes' to the question, 'Do you know what an e-cigarette is?' We interpreted this as they were aware of e-cigarettes. Thus, the final sample analysed for this study was 583 people who were asked about their beliefs of the harmful effects of e-cigarettes and about their usefulness for reducing or quitting smoking.

We used four separate questions to assess independently the absolute perception about harmfulness for e-cigarette users, harmfulness for passively exposed non-e-cigarette users, usefulness of cigarette cessation for smokers, and usefulness of cigarette reduction for smokers. We used the following two questions to measure the perception or beliefs about the harmful effects of e-cigarettes: "Do you think that electronic cigarettes can be harmful to the health of users?" and "Do you think that electronic cigarettes can be harmful to the health of people that are near users and who are passively exposed?" We also used the following two questions to measure the perception or beliefs about ecigarette usefulness: "Do you think that electronic cigarettes can be useful for quitting smoking?" and "Do you think that electronic cigarettes can be useful for reducing cigarette consumption?" There were five possible answers to these questions: 'totally agree', 'agree', 'neither agree nor disagree', 'disagree', and 'totally disagree'. When participants answered 'totally agree' or 'agree', we interpreted this to mean that the participants had the perception or belief that e-cigarettes had harmful effects and that e-cigarettes were useful for reducing or eliminating tobacco consumption according to the specific questions. We dichotomised the variable in agree ('totally agree' and 'agree') and disagree ('neither agree nor disagree', 'disagree' and 'totally disagree') in order to perform the paired comparisons between the perception of harmful effects and of usefulness of e-cigarettes. We did not include the answer 'neither agree nor disagree' in the agree category for not overestimating the perception of the population.

We calculated the percentages and ORs with 95\% CI of the perception about harmfulness for e-cigarette users, harmfulness for exposed non-e-cigarette users, usefulness of cigarette cessation for smokers, and usefulness of cigarette reduction for smokers according to all independent variables studies. We calculated the ORs by means of logistic regression models adjusted for sex, age and educational level. We performed four paired comparisons: (1) comparison of the percentages of people who perceived that e-cigarettes have harmful effects on users vs on people passively exposed to e-cigarettes; (2) comparison of the percentages of people who perceived that e-cigarettes were useful for quitting tobacco smoking vs for reducing tobacco smoking; (3) comparison of the percentages of people who perceived that ecigarettes have harmful effects on users vs are useful for quitting tobacco smoking; and (4) Comparison of the 
percentages of people who perceived that e-cigarettes have harmful effects on users vs are useful for reducing tobacco smoking. For all paired comparisons of the perception or belief of harmful effects and usefulness of ecigarettes, we used McNemar's $\chi^{2}$ test. All analyses (percentages, ORs and paired comparisons) were stratified by sex; age (categorised as young adults: 25-44; adults: 45-64; and the elderly: $\geq 65$ years); educational level (categorised as low: no education or up to a middle school diploma; intermediate: high school; or high: university degree); cigarette smoking status (categorised as current smokers: participants who smoked cigarettes daily or occasionally at the moment of the survey; former smokers: participants who did not smoke cigarettes at the moment of the survey but had smoked cigarettes in the past; and never-smokers: participants who have never smoked cigarettes); and level of nicotine dependence for current cigarette smokers as measured with the Fagerström Test for Cigarette Dependence (FTCD) ${ }^{15}$ categorised as low-medium dependence (scores from 0 to 5 ) or high dependence (scores $\geq 6$ ). We also gathered information on ever use of e-cigarettes using the question: 'Have you ever used e-cigarettes?' The possible answers to this question were: 'yes, currently', 'yes, in the past', 'I have only tried e-cigarettes', and 'I have never used e-cigarettes'. We dichotomised the variables (yes/no) considering ever-users of ecigarettes as those people who answered 'yes, currently', 'yes, in the past' and 'I have only tried e-cigarettes', and never-users as those who had never used them.

\section{RESULTS}

In total, $54.3 \%$ of the sample followed up were females and $73.1 \%$ were older than 44 years $(36.3 \%$ were $45-64$ years and $36.8 \%$ were $\geq 65$ years). The prevalence of smokers of manufactured cigarettes was $23.3 \%$ and the prevalence of ever e-cigarette use was $6.5 \%$. The prevalence of ever e-cigarette use was higher among men, younger people and people with intermediate educational level. Ever e-cigarette users were predominantly current smokers (data not shown).

In our study, $79.2 \%$ of participants were aware of e-cigarettes. There were statistically significant differences between the people who were aware versus unaware of e-cigarettes in terms of age, educational level and current smoking status (table 1). Higher levels of awareness were found for younger people $(94.4 \%, 25-44$ years, $\mathrm{p}<0.001)$, for those with higher education levels $(90.6 \%, \mathrm{p}<0.001)$ and for current smokers $(93.6 \%, \mathrm{p}<0.001)$.

Of the participants who were aware of e-cigarettes, $40.1 \%$ believed that e-cigarettes have harmful effects on users and $27.1 \%$ believed that e-cigarettes have harmful effects on people who are passively exposed to e-cigarettes $(p<0.001)$. There were no statistically significant differences in the percentages of participants who believed e-cigarettes have a harmful effect for users in terms of sex, age, educational level, smoking status, FTCD or ever e-cigarette use (table 2). More neversmokers than current smokers believed that e-cigarettes have potentially harmful effects on people passively exposed to e-cigarettes $(34.4 \%$ vs $20.6 \%$; OR $=1.93,95 \%$ CI 1.02 to 3.63 ); there were no statistically significant differences in the other variables (table 2). The proportion of individuals holding perceptions about harmful effects of e-cigarettes on users was systematically higher than the proportion of individuals holding perceptions about harmful effects of e-cigarettes on people who were passively exposed to them across all the variables studied. The differences between the perceived harmful effects for users and for those passively exposed to e-cigarettes were higher among women, older people, lower

Table 1 Sociodemographic differences between the people aware of and not aware of electronic cigarettes

\begin{tabular}{|c|c|c|c|}
\hline & $\begin{array}{l}\text { Yes, I have heard of } \\
\text { electronic cigarettes } \\
(n=583)\end{array}$ & $\begin{array}{l}\text { No, I have not heard } \\
\text { of electronic cigarettes } \\
(n=153)\end{array}$ & p Value \\
\hline Sex & & & $0.152^{*}$ \\
\hline Males & 47.0 & 40.5 & \\
\hline Females & 53.0 & 59.5 & \\
\hline Age (years) & & & $<0.001^{*}$ \\
\hline 25-44 & 32.1 & 7.2 & $<0.001 \dagger$ \\
\hline $45-64$ & 41.2 & 17.6 & \\
\hline$\geq 65$ & 26.7 & 75.2 & \\
\hline Educational level & & & $<0.001^{*}$ \\
\hline Low & 14.6 & 49.7 & \\
\hline Intermediate & 40.6 & 32.7 & $<0.001 \dagger$ \\
\hline High & 44.8 & 17.6 & \\
\hline Smoking status & & & $<0.001^{*}$ \\
\hline Never-smokers & 35.3 & 60.1 & \\
\hline Former smokers & 37.2 & 32.7 & \\
\hline Current smokers & 27.5 & 7.2 & \\
\hline
\end{tabular}


Table 2 Percentages, ORs and $95 \% \mathrm{Cl}$ for the responses "agree" or "totally agree" to questions about the harmful effects of e-cigarettes on users and on people passively exposed to e-cigarettes and to questions about the usefulness of e-cigarettes for quitting and for reducing tobacco consumption among the general population in Barcelona who were aware of e-cigarettes ( $\mathrm{n}=583$ ), Spain (2013-2014)

\begin{tabular}{|c|c|c|c|c|c|c|c|c|c|c|c|c|c|}
\hline & \multirow[b]{3}{*}{$\mathbf{n}$} & \multicolumn{4}{|c|}{ Belief of harmful effects of e-cigarettes } & \multirow[b]{3}{*}{ p Valueł } & \multicolumn{5}{|c|}{ Belief of usefulness of e-cigarettes } & \multicolumn{2}{|c|}{ Comparisons ${ }^{\star}$} \\
\hline & & \multicolumn{2}{|l|}{ On users } & \multicolumn{2}{|c|}{$\begin{array}{l}\text { On non-users passively } \\
\text { exposed }\end{array}$} & & \multicolumn{2}{|c|}{ For quitting smoking } & \multicolumn{2}{|c|}{ For reducing smoking } & \multirow[b]{2}{*}{ p Value§ } & \multirow[b]{2}{*}{ p Valueף } & \multirow[b]{2}{*}{ p Value ${ }^{*}$} \\
\hline & & Per cent & ORt (95\% Cl) & Per cent & ORt (95\% Cl) & & Per cent & ORt $(95 \% \mathrm{Cl})$ & Per cent & $\mathrm{ORT}(95 \% \mathrm{Cl})$ & & & \\
\hline Overall & 583 & 40.1 & - & 27.1 & - & $<0.001$ & 29.9 & - & 50.6 & - & $<0.001$ & 0.047 & 0.044 \\
\hline \multicolumn{14}{|l|}{ Sex } \\
\hline Male & 274 & 38.7 & 1 & 26.5 & 1 & 0.001 & 35.2 & 1.65 (1.12 to 2.45$)$ & 49.4 & 1 & $<0.001$ & 0.755 & 0.095 \\
\hline Female & 309 & 41.3 & $1.16(0.75$ to 1.78$)$ & 27.7 & 1.15 (0.70 to 1.87$)$ & $<0.001$ & 25.1 & 1 & 51.6 & $1.10(0.78$ to 1.56$)$ & $<0.001$ & 0.017 & 0.281 \\
\hline \multicolumn{14}{|l|}{ Age (years) } \\
\hline $25-44$ & 187 & 37.2 & 1 & 24.6 & 1 & 0.002 & 34.7 & 1.64 (0.91 to 2.96$)$ & 56.9 & 1.56 (0.95 to 2.58$)$ & $<0.001$ & 0.906 & 0.010 \\
\hline $45-64$ & 240 & 37.8 & 1.04 (0.63 to 1.72$)$ & 25.4 & $1.06(0.60$ to 1.88$)$ & 0.013 & 28.6 & 1.29 (0.74 to 2.27$)$ & 49.1 & $1.17(0.74$ to 1.87$)$ & $<0.001$ & 0.289 & 0.193 \\
\hline$\geq 65$ & 156 & 49.3 & $1.73(0.90$ to 3.31$)$ & 35.2 & 2.03 (0.99 to 4.18 ) & 0.016 & 24.8 & 1 & 43.8 & 1 & $<0.001$ & 0.003 & 0.360 \\
\hline \multicolumn{14}{|l|}{ Educational level } \\
\hline Low & 85 & 44.1 & 0.99 (0.51 to 1.92$)$ & 25.0 & 1 & 0.031 & 27.5 & 1 & 43.8 & 1 & 0.002 & 0.377 & 1.000 \\
\hline Intermediate & 237 & 39.0 & 1 & 28.6 & 1.66 (0.75 to 3.68$)$ & 0.012 & 27.7 & 0.84 (0.44 to 1.62 ) & 49.3 & $1.13(0.65$ to 1.97$)$ & $<0.001$ & 0.201 & 0.278 \\
\hline High & 261 & 39.5 & $1.08(0.66$ to 1.74$)$ & 26.5 & 1.61 (0.70 to 3.72$)$ & 0.002 & 32.6 & $1.00(0.52$ to 1.92$)$ & 53.8 & 1.25 (0.71 to 2.22$)$ & $<0.001$ & 0.314 & 0.045 \\
\hline \multicolumn{14}{|l|}{ Smoking status } \\
\hline Never-smokers & 206 & 42.3 & $1.10(0.63$ to 1.90$)$ & 34.4 & 1.93 (1.02 to 3.63 ) & 0.180 & 29.2 & 1.15 (0.71 to 1.86$)$ & 47.8 & 0.98 (0.65 to 1.49$)$ & $<0.001$ & 0.043 & 1.000 \\
\hline Former smokers & 217 & 39.8 & 0.98 (0.56 to 1.73$)$ & 25.2 & 1.19 (0.61 to 2.30$)$ & 0.004 & 26.8 & 1 & 47.1 & 1 & $<0.001$ & 0.253 & 0.470 \\
\hline Current smokers & 160 & 37.5 & 1 & 20.6 & 1 & $<0.001$ & 35.0 & 1.37 (0.83 to 2.26$)$ & 58.4 & 1.50 (0.95 to 2.35$)$ & $<0.001$ & 1.000 & 0.012 \\
\hline \multicolumn{14}{|l|}{ FTCD } \\
\hline Low-Medium (0-5) & 133 & 37.8 & 1.05 (0.38 to 2.92$)$ & 21.3 & 1.25 (0.35 to 4.39$)$ & 0.002 & 35.1 & 1.11 (0.41 to 3.03$)$ & 56.1 & 1 & $<0.001$ & 1.000 & 0.058 \\
\hline High $(6-10)$ & 27 & 36.4 & 1 & 18.2 & 1 & 0.250 & 34.8 & 1 & 69.2 & 1.71 (0.68 to 4.33$)$ & 0.008 & 1.000 & 0.111 \\
\hline \multicolumn{14}{|c|}{ Have you ever used an e-cigarette? } \\
\hline No & 535 & 40.1 & 0.93 (0.46 to 1.88$)$ & 28.6 & 2.03 (0.81 to 5.11$)$ & $<0.001$ & 29.3 & 1 & 50.0 & 1 & $<0.001$ & 0.052 & 0.107 \\
\hline Yes & 48 & 39.5 & 1 & 15.8 & 1 & $<0.001$ & 35.6 & 1.22 (0.63 to 2.37$)$ & 56.5 & 1.23 (0.65 to 2.30$)$ & 0.004 & 0.824 & 0.189 \\
\hline
\end{tabular}

${ }^{*}$ Comparisons between the perception of harmful effects on users and the usefulness of e-cigarettes for quitting or reducing smoking

†Adjusted ORs for sex, age and educational level.

$\ddagger$ Comparison of the percentages of people who perceived that e-cigarettes have harmful effects on users and on people passively exposed to e-cigarettes using McNemar's $\chi^{2}$ test.

$\S$ Comparison of the percentages of people who perceived that e-cigarettes were useful for quitting tobacco smoking and for reducing tobacco smoking using McNemar's $\chi^{2}$-test.

१Comparison of the percentages of people who perceived that e-cigarettes have harmful effects on users and were useful for quitting tobacco smoking using McNemar's $\chi^{2}$-test.

${ }^{\star *}$ Comparison of the percentages of people who perceived that e-cigarettes have harmful effects on users and were useful for reducing tobacco smoking using McNemar's $\chi^{2}$ test.

e-cigarette, electronic cigarette; FTCD, Fagerström Test for Cigarette Dependence. 
education level, current smokers and ever e-cigarette users (table 2).

The percentage of people who perceived that e-cigarettes were useful for quitting smoking and for reducing tobacco consumption was $29.9 \%$ and $50.6 \%$, respectively $(\mathrm{p}<0.001)$. A greater proportion of the sample believed e-cigarettes were useful for reducing tobacco consumption than for quitting smoking according to all the variables studied. These differences were statistically significant (table 2).

Among the sample, the proportion of individuals holding perceptions about e-cigarettes being useful for reducing tobacco consumption was sistematically higher than the proportion of individuals holding perceptions about their harmful effects on users (overall $=50.6 \%$ vs $40.1 \%, \mathrm{p}=0.044$ ); however, there were only statistically significant differences among young adult people (2544 years), those with a high educational level and current smokers (table 2).

\section{DISCUSSION}

Although previous studies ${ }^{8-12}$ focus on the perceptions about e-cigarettes, to the best of our knowledge, this is the first study that compares the general population's beliefs about the usefulness of e-cigarettes for reducing or eliminating smoking and their beliefs that e-cigarettes have potentially harmful effects. We found that more people believed that e-cigarettes are useful, particularly for reducing tobacco smoking, than people who believed that e-cigarettes have potentially harmful effects on users and on those passively exposed to them.

We did not find differences among the perception of harmful effects of e-cigarettes and their usefulness according to the use of e-cigarettes. However, a study conducted among young adults ${ }^{11}$ showed that participants who believed e-cigarettes can help to quit smoking were more likely to experiment with the e-cigarette in the future.

Current scientific evidence about the effectiveness of e-cigarettes for quitting smoking is contradictory and scarce. A meta-analysis ${ }^{16}$ based on 13 studies (2 randomised controlled trials and 11 cohort studies) has failed to prove that e-cigarettes help smokers to stop smoking in the long term compared with placebo e-cigarettes, and that e-cigarettes could help to prevent relapse among former smokers or that they could promote smoking cessation among current smokers. A recent longitudinal study, ${ }^{17}$ not included in the meta-analysis, has shown that quitting smoking might depend on the type of e-cigarettes used and the frequency of use. On the other hand, other studies ${ }^{12}{ }^{18}$ found a high percentage of 'dual' use (ie, use of e-cigarettes plus use of other tobacco products) and low satisfaction with the use of e-cigarette devices (including among e-cigarette users with nicotine). ${ }^{19}$ Moreover, smokers who have used e-cigarettes may be at increased risk for not being able to quit smoking. ${ }^{20}$ Our results show that the general population believes that e-cigarettes are more useful for reducing tobacco consumption than for quitting smoking ( $50 \%$ vs $30 \%$ of the population).

According to our data, the general population of Barcelona believes that e-cigarettes are more useful than harmful. We hypothesise that, at least in part, this is because conventional cigarettes are used as a reference by the general population (ie, e-cigarettes are compared with conventional cigarettes). One study conducted in adult smokers in the USA $(n=6007)^{21}$ found that smokers considered e-cigarettes as less likely to cause cancer or heart disease compared with conventional cigarettes. Other studies ${ }^{9}{ }^{10}$ have shown a high percentage of people who believe that e-cigarettes are less harmful than conventional cigarettes.

Currently, many e-cigarette companies promote e-cigarettes by stating that e-cigarette use can help to reduce or eliminate smoking and that e-cigarettes are a healthier option than smoking conventional cigarettes. ${ }^{22}$ Moreover, it is common for people to learn about e-cigarettes from traditional media sources, such as radio, newspapers and $\mathrm{TV}^{10}$ The increase in these kinds of advertisements and messages about e-cigarettes in the media and on social networks ${ }^{23-25}$ could create an erroneous 'imaginary collective idea' about the lack of harmful effects and the usefulness of e-cigarettes in the general population. For this reason, the WHO has recommended the regulation of e-cigarettes, including regulation of their advertising. ${ }^{26}$

Another important concern is the effect of passive exposure to e-cigarettes aerosols. We found that a low percentage, about $27 \%$ of the population, believed that passive exposure to e-cigarettes is harmful to non-users. Moreover, there was a higher perception that e-cigarettes are more harmful to users than to people passively exposed to them (40\% vs $27 \%$ of the population). However, attitudes towards e-cigarette regulation in indoor places are generally positive. ${ }^{27}$ Recent studies ${ }^{28-34}$ have found toxic and carcinogenic substances in the aerosol generated by e-cigarettes, such as nitrosamines, polyaromatic hydrocarbons, carbonyls, volatile organic compounds, heavy metals and nicotine. Notably, nonsmokers absorb nicotine when they are passively exposed to e-cigarettes at home, although the mean concentrations of nicotine are lower than those in non-smokers exposed to conventional cigarettes. ${ }^{35}$ Moreover, the nicotine residue (third-hand exposure to nicotine) in houses where e-cigarettes were used was significantly lower than in houses where conventional cigarettes were smoked. ${ }^{36}$

The main limitation of our study is the potential for participation bias due to the attrition in the cohort of participants. Although there were no statistically significant differences between the people who were followed up and those who were lost from the original study according to sex, age and educational level, our final sample had a greater proportion of older people than the population of the city of Barcelona. However, our results could be generalised to the rest of Spain and 
other European countries. Another potential limitation is the use of a questionnaire to collect self-reported information on e-cigarette use, which could be an inherent source of bias. We used a face-to-face questionnaire with trained interviewers, thus potentially increasing the internal validity of our results as compared with other studies that used internet-based and other selfadministered surveys. Although the use of a face-to-face questionnaire could also be a limitation when reporting substance use (ie, under-reporting of cocaine use), we believe that this limitation is scarce in our study because the use of e-cigarettes is not socially stigmatised. On the other hand, our results could partially underestimate the real perception of usefulness and harmfulness of e-cigarettes because we classified the answer 'neither agree nor disagree' in the 'disagree' category. However, we used the same categorisation in the four questions and this limitation is minimised in the comparisons.

In conclusion, the perception in the general population that e-cigarettes are useful, particularly in reducing tobacco smoking, is higher than the perception that e-cigarettes have harmful effects on users and those passively exposed to them. Advertisements and messages about the potentially harmful effects of e-cigarettes and their usefulness for reducing or eliminating smoking should be regulated and be based on scientific evidence to avoid creating any erroneous ideas about these devices in the general population.

\section{Author affiliations}

${ }^{1}$ Tobacco Control Unit, Cancer Prevention and Control Program, Institut Català d'Oncologia, L'Hospitalet de Llobregat, Barcelona, Spain

${ }^{2}$ Cancer Prevention and Control Group, Institut d'Investigació Biomèdica de Bellvitge-IDIBELL, L'Hospitalet de Llobregat, Barcelona, Spain

${ }^{3}$ Biostatistics Unit, Department of Basic Sciences, Universitat Internacional de Catalunya, Sant Cugat del Vallès, Barcelona, Spain

${ }^{4}$ Department of Clinical Sciences, School of Medicine, Universitat de Barcelona, Barcelona, Spain

${ }^{5}$ Addictions Unit, Institute of Neurosciences, Hospital Clínic de Barcelona, Barcelona, Spain

${ }^{6}$ Health Plan Directorate, Ministry of Health, Generalitat de Catalunya, Barcelona, Spain

${ }^{7}$ Department of Public Health, Universitat de Barcelona, Barcelona, Spain

Acknowledgements The authors thank Nuria Quirós for assistance with participant follow-up by linking the contact information with that of registrants in the Insurance Central Registry of Catalonia. They also thank Montse Ferré and Lucía Baranda for their coordination of the fieldwork. Moreover, they thank San Francisco Edit for the English revision of the last version of the manuscript.

Contributors JMM-S conceived the study. MB, MF, EF, ES and JMM-S contributed to the design and coordination of the study. JCM-S analysed the data. JMM-S drafted the first manuscript. All the authors contributed substantially to the interpretation of the data and to revising of the manuscript. All the authors approved its final version.

Funding This project was funded by the Instituto de Salud Carlos III, Government of Spain (RTICC, RD12/0036/0053 and PI12/01114), by the Ministry of Universities and Research, Government of Catalonia (grant 2009SGR192) and co-funded by ISCIII-Subdirección General de Evaluación and by FEDER funds/ European Regional Development Fund (ERDF)- a way to build Europe-.

Competing interests None declared.
Patient consent Obtained.

Ethics approval The Research and Ethics Committee of the Bellvitge University Hospital approved the study protocol.

Provenance and peer review Not commissioned; externally peer reviewed.

Data sharing statement No additional data are available.

Open Access This is an Open Access article distributed in accordance with the Creative Commons Attribution Non Commercial (CC BY-NC 4.0) license, which permits others to distribute, remix, adapt, build upon this work noncommercially, and license their derivative works on different terms, provided the original work is properly cited and the use is non-commercial. See: http:// creativecommons.org/licenses/by-nc/4.0/

\section{REFERENCES}

1. Regan AK, Promoff G, Dube SR, et al. Electronic nicotine delivery systems: adult use and awareness of the 'e-cigarette' in the USA. Tob Control 2013;22:19-23.

2. King BA, Alam S, Promoff G, et al. Awareness and ever-use of electronic cigarettes among U.S. adults, 2010-2011. Nicotine Tob Res 2013;15:1623-7.

3. Dutra LM, Glantz SA. Electronic cigarettes and conventional cigarette use among US adolescents: a cross-sectional study. JAMA Pediatr 2014;168:610-17.

4. Vardavas $\mathrm{Cl}$, Filippidis FT, Agaku IT. Determinants and prevalence of e-cigarette use throughout the European Union: a secondary analysis of 26566 youth and adults from 27 countries. Tob Control 2015:24:442-8.

5. Faculty of Public Health. Nicotine Science and Policy, Letter of concern by 53 public health experts to $\mathrm{WHO}$ with regard to the FCTC and electronic cigarettes. http://nicotinepolicy.net/documents/ letters/MargaretChan.pdf (accessed Aug 2015).

6. Centre for Tobacco Control, Research and Education. Letter of support from 129 public health experts for WHO's evidence based approach to electronic cigarettes. https://tobacco.ucsf.edu/sites/ tobacco.ucsf.edu/files/u9/Chan-letter-June16\%20PST\%20FINAL\% 20with\%20129\%20sigs.pdf (accessed Aug 2015)

7. Grana RA, Ling PM, Benowitz N, et al. Electronic cigarettes. Circulation 2014;129:e490-2.

8. Pepper JK, Brewer NT. Electronic nicotine delivery system (electronic cigarette) awareness, use, reactions and beliefs: a systematic review. Tob Control 2014;23:375-84.

9. Tan AS, Bigman CA. E-cigarette awareness and perceived harmfulness: prevalence and associations with smoking-cessation outcomes. Am J Prev Med 2014;47:141-9.

10. Martínez-Sánchez JM, Fu M, Ballbé M, et al. [Knowledge of electronic cigarettes and their perceived harmfulness among the adult population in Barcelona (Spain)]. Gac Sanit 2015;29:296-9.

11. Choi K, Forster JL. Beliefs and experimentation with electronic cigarettes: a prospective analysis among young adults. Am J Prev Med 2014;46:175-8.

12. Gallus S, Lugo A, Pacifici R, et al. E-cigarette awareness, use, and harm perception in Italy: a national representative survey. Nicotine Tob Res 2014;16:1541-8.

13. Fu M, Fernandez E, Martinez-Sanchez JM, et al. Salivary cotinine concentrations in daily smokers in Barcelona, Spain: a cross-sectional study. BMC Public Health 2009:9:320.

14. Martínez-Sánchez JM, Fernández E, Fu M, et al. Assessment of exposure to secondhand smoke by questionnaire and salivary cotinine in the general population of Barcelona, Spain (2004-2005). Prev Med 2009;48:218-23.

15. Fagerström K. Determinants of tobacco use and renaming the FTND to the Fagerstrom Test for Cigarette Dependence. Nicotine Tob Res 2012;14:75-8

16. McRobbie H, Bullen $\mathrm{C}$, Hartmann-Boyce J, et al. Electronic cigarettes for smoking cessation and reduction. Cochrane Database Syst Rev 2014;(12):CD010216

17. Hitchman SC, Brose LS, Brown J, et al. Associations between E-cigarette type, frequency of use, and quitting smoking: findings from a longitudinal online panel survey in Great Britain. Nicotine Tob Res 2015; 17:1187-94.

18. Pearson JL, Richardson A, Niaura RS, et al. e-Cigarette awareness, use, and harm perceptions in US adults. Am J Public Health 2012:102:1758-66.

19. Martínez-Sánchez JM, Ballbè M, Fu M, et al. Electronic cigarette use among adult population: a cross-sectional study in Barcelona, Spain (2013-2014). BMJ Open 2014;4:e005894. 
20. Al-Delaimy WK, Myers MG, Leas EC, et al. E-cigarette use in the past and quitting behavior in the future: a population-based study. Am J Public Health 2015;105:1213-19.

21. Pepper JK, Emery SL, Ribisl KM, et al. How risky is it to use e-cigarettes? Smokers' beliefs about their health risks from using novel and traditional tobacco products. J Behav Med 2015;38:318-26.

22. Grana RA, Ling PM. "Smoking revolution": a content analysis of electronic cigarette retail websites. Am J Prev Med 2014;46:395-403.

23. Pepper JK, Emery SL, RibisI KM, et al. Effects of advertisements on smokers' interest in trying e-cigarettes: the roles of product comparison and visual cues. Tob Control 2014;23(Suppl 3): iii31-6.

24. Huang J, Kornfield R, Szczypka G, et al. A cross-sectional examination of marketing of electronic cigarettes on Twitter. Tob Control 2014;23(Suppl 3):iii26-30.

25. de Andrade M, Hastings G, Angus K. Promotion of electronic cigarettes: tobacco marketing reinvented? BMJ 2013;347: f7473.

26. World Health Organization. Conference of the Parties to the WHO Framework Convention on Tobacco Control. Provisional agenda item 4.4.2. http://apps.who.int/gb/fctc/PDF/cop6/FCTC_COP6_10-en.pdf? ua=1 (accessed Aug 2015).

27. Martínez-Sánchez JM, Ballbe M, Fu M, et al. Attitudes towards electronic cigarettes regulation in indoor workplaces and selected public and private places: a population-based cross-sectional study. PLOS ONE 2014;9:e114256.
28. Bekki K, Uchiyama S, Ohta K, et al. Carbonyl compounds generated from electronic cigarettes. Int J Environ Res Public Health 2014;11:11192-200.

29. Goniewicz ML, Kuma T, Gawron M, et al. Nicotine levels in electronic cigarettes. Nicotine Tob Res 2013;15:158-66.

30. McAuley TR, Hopke PK, Zhao J, et al. Comparison of the effects of e-cigarette vapor and cigarette smoke on indoor air quality. Inhal Toxicol 2012;24:850-7.

31. Uchiyama S, Ohta K, Inaba Y, et al. Determination of carbonyl compounds generated from the E-cigarette using coupled silica cartridges impregnated with hydroquinone and

2,4-dinitrophenylhydrazine, followed by high-performance liquid chromatography. Anal Sci 2013;29:1219-22.

32. Williams M, Villarreal A, Bozhilov $\mathrm{K}$, et al. Metal and silicate particles including nanoparticles are present in electronic cigarette cartomizer fluid and aerosol. PLOS ONE 2013;8:e57987.

33. Czogala J, Goniewicz ML, Fidelus B, et al. Secondhand exposure to vapors from electronic cigarettes. Nicotine Tob Res 2014;16:655-62.

34. Schober W, Szendrei K, Matzen W, et al. Use of electronic cigarettes (e-cigarettes) impairs indoor air quality and increases FeNO levels of e-cigarette consumers. Int $J$ Hyg Environ Health 2014;217:628-37.

35. Ballbé M, Martínez-Sánchez JM, Sureda X, et al. Cigarettes vs. e-cigarettes: passive exposure at home measured by means of airborne marker and biomarkers. Environ Res 2014;135:76-80.

36. Bush D, Goniewicz ML. A pilot study on nicotine residues in houses of electronic cigarette users, tobacco smokers, and non-users of nicotine-containing products. Int J Drug Policy 2015;26:609-11. 